\title{
Younger patients have poorer biochemical outcome after radical prostatectomy in high-risk prostate cancer
}

\author{
Sung Kyu Hong, Jung Soo Nam, Woong Na, Jong Jin Oh, Cheol Yong Yoon, Chang Wook Jeong, Hyun June Kim, \\ Seok-Soo Byun and Sang Eun Lee
}

The aim of this study was to investigate the prognostic significance of patient age with respect to tumour aggressiveness in men who underwent radical prostatectomy (RP) for prostate cancer. In this study, we reviewed the records of 743 patients who received RP without neoadjuvant or adjuvant therapy at our institution and were followed up for $>\mathbf{2}$ years postoperatively. For our analyses, the patients were divided into two groups according to age: younger ( $<60$ years) and older ( $\geqslant 60$ years). Through uni- and multivariate analyses, associations of various clinicopathological parameters, including biochemical recurrence-free survival, with patient age, were evaluated among all patients, and the patients were stratified according to their D'Amico risk classification. Among all subjects, younger $(n=126)$ and older $(n=617)$ patients showed no significant differences regarding pathological parameters and biochemical recurrence-free survival $(P=0.288)$. For the high-risk group $(n=206)$, younger patients had a lower rate of biochemical recurrence-free survival following surgery than older patients $(P=0.017)$, despite the fact that no significant differences were observed regarding various known prognostic parameters between the two age groups. In addition, multivariate analysis revealed that age was an independent predictor of biochemical recurrence-free survival among the high-risk group $(P=0.003)$. Our results showed that relatively younger patients have a comparable biochemical outcome compared with their older counterparts following RP performed for prostate cancer. However, among patients with high-risk disease, younger patients have a worse biochemical outcome following RP compared with older patients.

Asian Journal of Andrology (2011) 13, 719-723; doi:10.1038/aja.2011.39; published online 27 June 2011

Keywords: age factors; biochemical outcome; prostate; prostatic neoplasms; prostatectomy

\section{INTRODUCTION}

The number of young men who are treated for prostate cancer with radical prostatectomy (RP) is increasing. ${ }^{1-4}$ This phenomenon may largely be attributed to widespread prostate-specific antigen (PSA) testing and increased public awareness about prostate cancer. Considering their longer life expectancy, young men with prostate cancer can be regarded as a delicate group of patients to manage. Because the number of younger prostate cancer patients is expected to increase over time, urologists may soon be burdened even more with dilemmas in managing these young patients. $^{5,6}$

Meanwhile, the natural history of prostate cancer is still poorly understood, and the prognostic significance of patient age in prostate cancer remains controversial. Previous reports have demonstrated that younger men tend to have more aggressive prostate cancer and poorer outcomes after RP, whereas others have reported the contrary or indicated that age is not a significant prognostic factor regarding prostate cancer. ${ }^{4,7-16}$ We hypothesized that the prognostic significance of patient age may differ according to the clinicopathological profile of the tumour. Thus, we investigated the prognostic significance of patient age according to tumour aggressiveness in men who underwent RP for prostate cancer.

\section{MATERIALS AND METHODS}

Patient selection

After receiving approval from our institutional review board, we reviewed the records of 761 patients who received RP for prostate cancer between November 2003 and June 2008 at our institution and were followed up for more than 2 years postoperatively. After excluding patients who underwent neoadjuvant or adjuvant hormone or radiation therapy and those patients with missing data, a total of 743 patients were included in our study.

\section{Analysis data}

Various clinicopathological data, including patient age, preoperative PSA, body mass index, prostate volume (RP specimen weight), biopsy/ pathological Gleason score, clinical/pathological tumour stage, surgical margin status and postoperative follow-up PSA data, were assessed for each subject. Lymph node dissection was not routinely performed in our subjects. Data on the lymph node status were not available for all patients. RP specimens were weighed, measured and fixed in $10 \%$ neutral formalin. Subsequently, the apex and base were amputated and serially sectioned at $3-5 \mathrm{~mm}$ intervals in the vertical parasagittal plane. The seminal vesicles were sectioned parallel to their junction with the prostate and submitted entirely for evaluation. The 
remaining specimens were serially sectioned at $3-5 \mathrm{~mm}$ intervals perpendicular to the long axis of the gland from the apex to the base and stained with haematoxylin and eosin for histological evaluation.

In our study, biochemical recurrence was defined as two consecutive increases in PSA $\geqslant 0.2 \mathrm{ng} \mathrm{ml}^{-1}$ in at least 2 months following RP. ${ }^{17}$ For our analyses, the patients were divided into two groups according to age: $<60$ years and $\geqslant 60$ years. Associations of various clinicopathological parameters and patient age were evaluated among all patients, and the patients were stratified according to their D'Amico risk classification: low risk (clinical T1c-T2a, a PSA level $\leqslant 10 \mathrm{ng} \mathrm{ml}^{-1}$ and biopsy Gleason score $\leqslant 6$ ), intermediate risk (clinical stage T2b disease or PSA level of $10.1-20 \mathrm{ng} \mathrm{ml}^{-1}$ or biopsy Gleason score $=7$ ) and high risk (clinical stage T2c or PSA level $>20 \mathrm{ng} \mathrm{ml}^{-1}$ or biopsy Gleason score $\left.8-10\right) .{ }^{18}$

\section{Statistical analyses}

The SPSS software package version 15.0 (SPSS Inc., Chicago, IL, USA) was used for statistical analysis. Student paired $t$-test, chi-square analysis or analysis of variance was used to compare the groups of subjects. The biochemical recurrence-free survival rates for patient cohorts were estimated via the Kaplan-Meier method. Log-rank tests were used to compare survival curves. Multivariate analysis was performed according to the Cox proportional hazards regression model to identify independent predictive factors for biochemical recurrencefree survival. All $P$ values were two-sided, and $P<0.05$ indicated a significant result.

\section{RESULTS}

Patient characteristics were shown in Table 1. For the 743 patients included in our study, the median follow-up was 39.4 (range: 24-67)

Table 1 Clinicopathological characteristics of patients according to age $(n=743)$

\begin{tabular}{|c|c|c|c|}
\hline \multirow[t]{2}{*}{ Characteristics } & \multicolumn{2}{|c|}{ Groups } & \multirow[t]{2}{*}{$\mathrm{P}$ value } \\
\hline & Age $<60$ years & Age $\geqslant 60$ years & \\
\hline No. of patients (\%) & $126(17)$ & $617(83)$ & \\
\hline Mean follow-up (months) & 40.0 & 38.1 & 0.162 \\
\hline Mean BMI $\left(\mathrm{kg} \mathrm{m}^{-2}\right)$ & 24.2 & 24.4 & 0.395 \\
\hline Mean PSA (ng ml ${ }^{-1}$ ) & 11.1 & 11.9 & 0.537 \\
\hline Mean prostate specimen weight (g) & 34.9 & 41.6 & $<0.001$ \\
\hline Biopsy Gleason score (\%) & & & 0.826 \\
\hline$\leqslant 6$ & $67(53.2)$ & $312(50.6)$ & \\
\hline 7 & $43(34.1)$ & $216(35.0)$ & \\
\hline$\geqslant 8$ & $16(12.7)$ & $89(14.4)$ & \\
\hline Clinical stage (\%) & & & 0.334 \\
\hline T1c & $80(63.5)$ & $350(56.7)$ & \\
\hline $\mathrm{T} 2 \mathrm{a}, \mathrm{b}$ & $42(33.3)$ & $235(38.2)$ & \\
\hline $\mathrm{T} 2 \mathrm{C}$ & $4(3.2)$ & $32(5.2)$ & \\
\hline Pathological Gleason score (\%) & & & 0.116 \\
\hline$\leqslant 6$ & $42(33.4)$ & $152(24.7)$ & \\
\hline 7 & 73 (57.9) & $395(64.0)$ & \\
\hline$\geqslant 8$ & $11(8.7)$ & 70 (11.3) & \\
\hline Extracapsular extension (\%) & $32(25.4)$ & $196(31.8)$ & 0.158 \\
\hline Seminal vesicle invasion (\%) & $11(8.7)$ & $55(8.9)$ & 0.947 \\
\hline Positive surgical margin (\%) & $40(31.7)$ & $216(35.0)$ & 0.483 \\
\hline D’Amico risk group (\%) & & & 0.390 \\
\hline Low & $52(41.3)$ & $225(36.5)$ & \\
\hline Intermediate & $45(35.7)$ & $215(34.8)$ & \\
\hline High & $29(23.0)$ & $177(28.7)$ & \\
\hline
\end{tabular}

Abbreviations: BMI, body mass index; PSA, prostate-specific antigen. months. In comparison with patients younger than 60 years, older patients demonstrated larger prostate size (mean prostate specimen weight) $(P<0.001)$. Meanwhile, the two groups showed no significant differences regarding other various clinicopathological parameters, including preoperative PSA level, pathological stage and pathological Gleason score. Nerve-sparing procedure was performed in $84.9 \%$ of younger ( $<60$ years) and $50.6 \%$ of older ( $\geqslant 60$ years) patients, respectively $(P<0.001)$.

Younger ( $<60$ years) and older $(\geqslant 60$ years) patients demonstrated no significant difference $(P=0.288)$ in terms of biochemical recurrence-free survival after RP $(P=0.228$; Figure 1$)$. For the two age groups, the median 5-year biochemical recurrence-free survivals were $76.2 \%$ and $73.7 \%$ in younger and older patients, respectively. The median times to biochemical recurrence for the younger and older groups were 35.4 and 34.5 months, respectively $(P=0.574)$.

Among the 743 total patients, 277 (37.3\%), 260 (35.0\%) and 206 $(27.7 \%)$ patients had low-, intermediate- and high-risk disease, respectively, according to D'Amico risk classification. When these three groups of patients were analysed according to age ( $<60$ years $v s . \geqslant 60$ years), no significant differences in various clinicopathological parameters, including preoperative PSA level, pathological stage, pathological Gleason score and biochemical recurrence-free survival, were observed according to age in the low- and intermediate-risk groups (all $P>0.05$ ). In multivariate analyses, age was not a significant predictor of biochemical recurrence-free survival among both low$(P=0.322)$ and intermediate- $(P=0.347)$ risk groups. Meanwhile, for the high-risk group only, no significant differences in various clinicopathological parameters were observed according to age (Table 2). In analysing the nodal status of the high-risk group, 18 of $29(62.1 \%)$ younger patients and 92 of $177(52.0 \%)$ older patients had lymph node dissection during RP $(P=0.313)$. Among these patients who received nodal dissection, $7(24.1 \%)$ and 21 patients $(11.9 \%)$ from the younger and older groups, respectively, had positive nodes $(P=0.074)$. Also, no significant difference in the rate of performing nerve-sparing procedure was observed between younger $(10.3 \%)$ and older patients $(11.9 \%)$ in the high-risk group $(P=0.715)$. However, younger patients demonstrated a lower rate of biochemical recurrence-free survival than older patients in the high-risk group

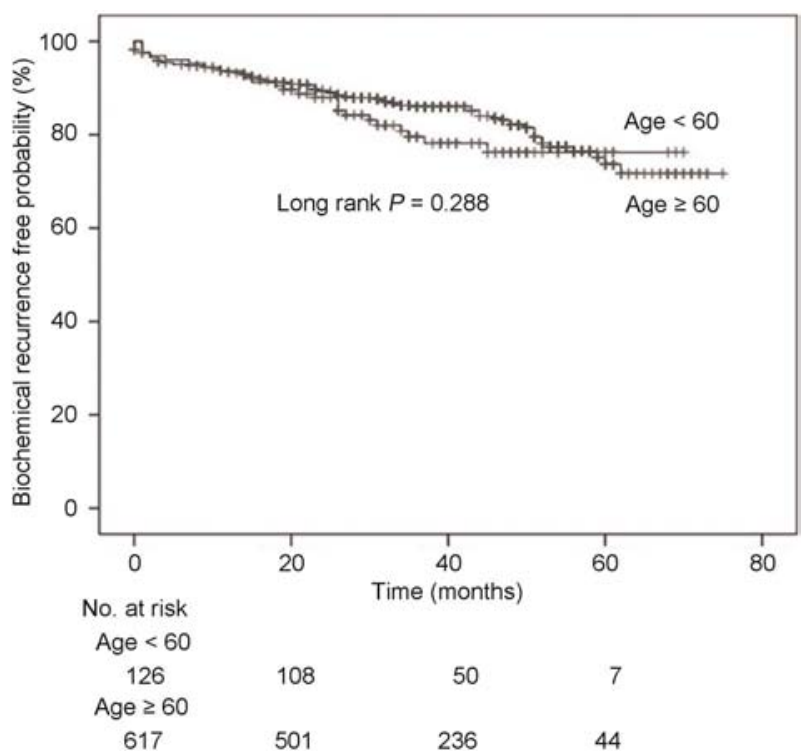

Figure 1 Biochemical recurrence-free survival after radical prostatectomy according to age ( $<60$ years $v s . \geqslant 60$ years) among all patients. 
Table 2 Clinicopathological characteristics of the high-risk group according to age $(n=206)$

\begin{tabular}{|c|c|c|c|}
\hline \multirow[t]{2}{*}{ Characteristics } & \multicolumn{2}{|c|}{ Group } & \multirow[t]{2}{*}{ P value } \\
\hline & Age $<60$ years & Age $\geqslant 60$ years & \\
\hline No. of patients (\%) & $29(14.1)$ & $177(85.9)$ & \\
\hline Mean follow-up (months) & 38.1 & 37.2 & 0.774 \\
\hline Mean BMI $\left(\mathrm{kg} \mathrm{m}^{-2}\right)$ & 24.0 & 24.5 & 0.335 \\
\hline Mean PSA (ng ml ${ }^{-1}$ ) & 23.8 & 22.5 & 0.750 \\
\hline Mean prostate specimen weight (g) & 37.4 & 41.9 & 0.122 \\
\hline Biopsy Gleason score (\%) & & & 0.826 \\
\hline$\leqslant 6$ & $5(17.2)$ & 30 (16.9) & \\
\hline 7 & $8(27.6)$ & $58(32.8)$ & \\
\hline$\geqslant 8$ & $16(55.2)$ & $89(50.3)$ & \\
\hline Clinical stage (\%) & & & 0.191 \\
\hline $\mathrm{T} 1 \mathrm{c}$ & $14(48.3)$ & $55(31.1)$ & \\
\hline $\mathrm{T} 2 \mathrm{a}, \mathrm{b}$ & $11(37.9)$ & $90(50.8)$ & \\
\hline $\mathrm{T} 2 \mathrm{C}$ & $4(13.8)$ & $32(18.1)$ & \\
\hline Pathological Gleason score (\%) & & & 0.674 \\
\hline$\leqslant 6$ & $3(10.3)$ & $11(6.2)$ & \\
\hline 7 & $16(55.2)$ & $108(61.0)$ & \\
\hline$\geqslant 8$ & $10(34.5)$ & $58(32.8)$ & \\
\hline Extracapsular extension (\%) & $15(51.7)$ & $100(56.5)$ & 0.631 \\
\hline Seminal vesicle invasion (\%) & $8(27.6)$ & $49(27.7)$ & 0.991 \\
\hline Confirmed nodal involvement (\%) & $7(24.1)$ & 21 (11.9) & 0.074 \\
\hline Positive surgical margin (\%) & $14(48.3)$ & $98(55.4)$ & 0.477 \\
\hline Nerve-sparing approach (\%) & $3(10.3)$ & $21(11.9)$ & 0.715 \\
\hline
\end{tabular}

Abbreviations: BMI, body mass index; PSA, prostate-specific antigen.

$(P=0.017)$ (Figure 2). The median times to biochemical recurrence for younger and older patients in the high-risk group were 34.3 and 66.1 months, respectively $(P=0.017)$. In addition, multivariate analysis revealed that age $(P=0.001)$, pathological Gleason score $(P=0.002)$ and seminal vesicle invasion $(P=0.003)$ were independent predictors of biochemical recurrence-free survival in the high-risk group (Table 3 ).

\section{DISCUSSION}

Among the patients included in our study, there were no significant differences in various clinicopathological profile and PSA outcome between younger $(<60$ years) and older $(\geqslant 60$ years $)$ patients who underwent RP for prostate cancer. However, when only the patients with high-risk disease were analysed, the younger patients had significantly lower biochemical recurrence-free survival following RP than their older counterparts. Also, among patients with high-risk disease, patient age was an independent predictor of biochemical recurrencefree survival. These findings suggest that age may be a significant prognostic factor among patients who undergo RP for more aggressive prostate cancer.

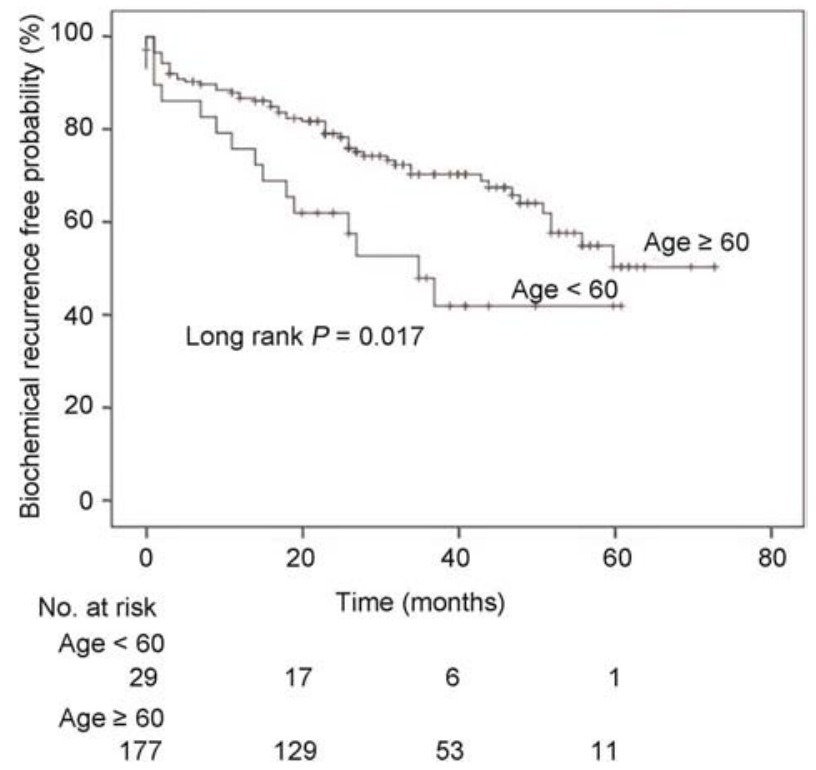

Figure 2 Biochemical recurrence-free survival after radical prostatectomy according to age ( $<60$ years vs. $\geqslant 60$ years) among patients with high-risk disease.

Despite the fact that younger adult patients have been reported to have worse prognosis in some cancers, younger age at diagnosis has generally been acknowledged as an indicator of a relatively better prognosis for various malignancies. ${ }^{18,19,20}$ Potential explanations for younger cancer patients having better prognoses include earlier detection of cancer, less severe stage of disease at diagnosis and superior general conditions for the younger patients. However, the role of age in the prognosis of prostate cancer is controversial. In the pre-PSA era, younger patients with prostate cancer were reported to have a more aggressive disease, leading to the conclusion that a young age at diagnosis is associated with a worse disease outcome. ${ }^{7,8}$ However, more recent studies demonstrated trends of older patients having worse prognoses or patient age not having any prognostic significance among RP cohorts. Freedland et al. ${ }^{11}$ reported that men of 50 years old or younger had significantly lower biochemical recurrence rates after RP than did older men after RP, based on multivariate analysis. These authors mentioned that this phenomenon can be attributed to the fact that older men have a more aggressive form of disease, as previously reported by Stamey et al. ${ }^{21}$ Also, Loeb et al. ${ }^{15}$ reported that age was an independent predictor of biochemical recurrence following RP with men 70 years or older having prostate cancer of a higher stage and grade. In addition, Sun et al. ${ }^{16}$ found that prostate cancer patients

Table 3 Multivariate Cox proportional hazards model of predictive factors for biochemical recurrence-free survival after radical prostatectomy among the high-risk group $(n=206)$

\begin{tabular}{|c|c|c|c|}
\hline & Hazard ratio & $95 \% \mathrm{Cl}$ & $\mathrm{P}$ value \\
\hline Age $(\geqslant 60$ years $v s .<60$ years $)$ & 0.364 & $0.196-0.676$ & 0.001 \\
\hline Prostate-specific antigen ( $\geqslant 7 \mathrm{ng} \mathrm{ml}^{-1}$ vs. $<7 \mathrm{ng} \mathrm{ml}^{-1}$ ) & 1.379 & $0.667-2.852$ & 0.386 \\
\hline Prostate specimen weight & 1.773 & $1.136-3.181$ & 0.047 \\
\hline Pathological Gleason score & 1.496 & $1.166-1.921$ & 0.002 \\
\hline Extraprostatic extension of tumour & 1.347 & $0.667-2.720$ & 0.406 \\
\hline Seminal vesicle invasion & 2.314 & $1.334-4.013$ & 0.003 \\
\hline Confirmed nodal involvement & 1.865 & $0.998-2.328$ & 1.005 \\
\hline Nerve-sparing procedure performed & 1.151 & $0.595-1.875$ & 0.785 \\
\hline Surgical margin positivity & 1.045 & 0.547-1.999 & 0.893 \\
\hline
\end{tabular}


older than 70 years had higher-risk disease and poorer prognoses compared with prostate cancer patients 70 or younger during the PSA era. However, Richstone et al. ${ }^{14}$ observed that age was not independently associated with prostate cancer-specific survival despite the fact that older men had more severe stage cancer and higher Gleason scores. In addition, Magheli et al. ${ }^{13}$ reported that increased age was not associated with worse biochemical outcomes following RP and mentioned that age should not be considered an independent prognosticator for disease recurrence. From their results, the authors stated that age should not be used to define or identify patients at higher risk for biochemical failure after RP and that age should be considered a strong surrogate marker representing known prognostic indicators.

Few studies have reported on the prognostic significance of patient age analysed according to the aggressiveness of prostate cancer. Similar to our results, Siddiqui et al. ${ }^{12}$ reported that although younger patients overall had a similar survival to that of older counterparts after RP, progression-free survival was worse with younger age in patients with high-risk pathological findings. Also, Lin et al. ${ }^{4}$ analysed the Surveillance, Epidemiology, and End Results Program database and reported that younger men with a high grade and locally advanced prostate cancer had a particularly poor prognosis compared with older counterparts. In their series, the authors observed that prostate cancer-specific survival was similar between all age groups among patients with Gleason scores of 5-7. However, when they analysed patients with Gleason scores of 8-10, their youngest cohort showed decreased overall and prostate cancer-specific survival compared with older men. They found that high grade prostate cancer was associated with $>25 \%$ prostate cancer-related mortality at 10 years in men aged $<55$ years. Also, an examination of the Cancer of the Prostate Strategic Urologic Research Endeavor dataset demonstrated that younger men with metastatic prostate cancer were at higher risk of early death compared with older counterparts. ${ }^{22}$ Although the analysed parameters of outcome as well as selection and age grouping of subjects were different compared with our study, the results of these previous studies are supportive of our findings.

Looking at most published reports on the effect of patient age on the outcome after RP, it remains challenging to compare the results due to differences in study design. Various relevant studies on the subject applied different end points for analyses and different age cutoffs for stratifying subjects. In our study, no significant differences were observed between the two age cohorts regarding PSA level, pathological Gleason score, pathological stage and margin positivity among the high-risk group. Accordingly, it would be difficult to explain the observed difference in PSA outcomes based upon known prognostic variables. Because all of our subjects were Korean, race was not a factor. Also, although family history was not included in our analyses due to a lack of relevant data, the family history of prostate cancer has been reported to confer no significant influence on PSA outcome following RP. ${ }^{23,24}$ Therefore, we hypothesize that as yet unknown genetic or other intrinsic biological factors may have contributed to our findings. Additional studies are needed to provide more insights into the biology of high-risk prostate cancer.

As observed for other modes of primary therapy for prostate cancer, several reports have shown that age does not affect outcome after radiotherapy. ${ }^{25,26}$ Similar data have been reported on per manent prostate brachytherapy as well. ${ }^{27}$ Considering our findings, further studies are warranted on the impact of patient age on outcomes following non-surgical primary treatments, such as external beam radiation therapy and brachytherapy, according to the disease risk groups.
Our study may be limited by the retrospective nature of the study design. Also, due to the lack of long-term follow-up, PSA outcome rather than overall or cancer-specific survival was analysed in our study. Although biochemical recurrence is currently the most commonly applied parameter in analysing outcomes after RP, the results of our study may have differed if a different end point were used. Because the exact data on lymph node status were not available in all subjects, nodal status was only partially assessed. Also, the extent of the surgical margins was not routinely reported by pathologists. Because PSA screening is not as widely performed in Asia as in Western countries, the characteristics of our subjects may be considered different compared with Western patients. When compared with contemporary Western RP series, our subjects have more aggressive-looking disease. Accordingly, our results may not be applicable to patients of other origins. Further studies are needed in this regard.

Our results showed that relatively younger patients have a comparable biochemical outcome compared with their older counterparts following RP performed for prostate cancer. However, among only the patients with high-risk disease, younger patients had worse biochemical recurrence-free survival compared with older patients. This finding provides a strong argument for considering aggressive treatments, such as multimodality therapy, in younger patients with highrisk prostate cancer. Further investigation is needed to elucidate the exact biology of prostate cancer in younger men.

\section{AUTHOR CONTRIBUTIONS}

SKH and SEL conceived the study, participated in its design and coordination, and helped to draft the manuscript. JSN, WN, JJO, CWJ and HJK made substantial contributions to data acquisition and analysis. CYY and SB made substantial contributions to data analysis and critically revised the manuscript. All authors read and approved the final manuscript.

\section{COMPETING FINANCIAL INTERESTS}

The authors declare no conflict of interest.

1 Smith CV, Bauer JJ, Connelly RR, Seay T, Kane C et al. Prostate cancer in men age 50 years or younger: a review of the Department of Defense Center for Prostate Disease Research multicenter prostate cancer database. J Urol 2000; 164: 1964-7.

2 Aleman M, Karakiewicz PI, Kupelian P, Kattan MW, Graefen M et al. Age and PSA predict likelihood of organ-confined disease in men presenting with PSA less than $10 \mathrm{ng} / \mathrm{mL}$ : implications for screening. Urology 2003; 62: 70-4.

3 Khan MA, Han M, Partin AW, Epstein JI, Walsh PC. Long-term cancer control of radical prostatectomy in men younger than 50 years of age: update 2003. Urology 2003; 62: 86-91.

4 Lin DW, Porter M, Montgomery B. Treatment and survival outcomes in young men diagnosed with prostate cancer: a population-based cohort study. Cancer 2009; 115: 2863-71.

5 Gao X, Zhou JH, Li LY, Qiu JG, Pu XY. Laparoscopic radical prostatectomy: oncological and functional results of 126 patients with a minimum 3-year follow-up at a single Chinese institute. Asian J Androl 2009; 11: 548-56.

6 Takizawa I, Hara N, Nishiyama T, Kaneko M, Hoshii T et al. Oncological results, functional outcomes and health-related quality-of-life in men who received a radical prostatectomy or external beam radiation therapy for localized prostate cancer: a study on long-term patient outcome with risk stratification. Asian J Androl 2009; 11: 28390.

7 Tjaden HB, Culp DA, Flocks RH. Clinical adenocarcinoma of the prostate in patients under 50 years of age. J Urol 1965; 93: 618-21.

8 Johnson DE, Lanieri JP Jr, Ayala AG. Prostatic adenocarcinoma occurring in men under 50 years of age. J Surg Oncol 1972; 4: 207-16.

9 Riopel MA, Polacik TJ, Partin AW, Sauvageot J, Walsh PC et al. Radical prostatectomy in men less than 50 years old. Urol Oncol 1995; 1: 80-3.

10 Kotsis SV, Spenser SL, Peyser PA, Montie JE, Cooney KA. Early onset prostate cancer: predictors of clinical grade. J Urol 2002; 167: 1659-63. 
11 Freedland SJ, Presti JC Jr, Kane CJ, Aronson WJ, Terris MK et al. Do younger men have better biochemical outcomes after radical prostatectomy? Urology 2004; 63: 51822.

12 Siddiqui SA, Sengupta S, Slezak JM, Bergstralh EJ, Leibovich BC et al. Impact of patient age at treatment on outcome following radical retropubic prostatectomy for prostate cancer. J Urol 2006; 175: 952-7.

13 Magheli A, Rais-Bahrami S, Humphreys EB, Peck HJ, Trock BJ et al. Impact of patient age on biochemical recurrence rates following radical prostatectomy. J Urol 2007; 178: 1933-7.

14 Richstone L, Bianco FJ, Shah HH, Kattan MW, Eastham JA et al. Radical prostatectomy in men aged $>$ or $=70$ years: effect of age on upgrading, upstaging, and the accuracy of a preoperative nomogram. BJU Int 2008; 101: 541-6.

15 Loeb S, Hernandez DJ, Mangold LA, Humphreys EB, Agro M et al. Progression after radical prostatectomy for men in their thirties compared to older men. BJU Int 2008; 101: 1503-6.

16 Sun L, Caire AA, Robertson CN, George DJ, Polascik TJ et al. Men older than 70 years have higher risk prostate cancer and poorer survival in the early and late prostate specific antigen eras. J Urol 2009; 182: 2242-8.

17 Cookson MS, Aus G, Burnett AL, Canby-Hagino ED, D'Amico AV et al. Variation in the definition of biochemical recurrence in patients treated for localized prostate cancer: the American Urological Association Prostate Guidelines for Localized Prostate Cancer Update Panel report and recommendations for a standard in the reporting of surgical outcomes. J Urol 2007; 177: 540-5.

18 D'Amico AV, Whittington R, Malkowicz SB, Schultz D, Blank K et al. Biochemica outcome after radical prostatectomy, external beam radiation therapy, or interstitial radiation therapy for clinically localized prostate cancer. JAMA 1998; 280: 969-74.
19 Aebi S, Gelber S, Castiglione-Gertsch M, Gelber RD, Collins J et al. Is chemotherapy alone adequate for young women with oestrogen receptor-positive breast cancer? Lancet 2000; 355: 1869-74.

20 Bleyer A. Young adult oncology: the patients and their survival challenges. CA Cancer J Clin 2007; 57: 242-55.

21 Stamey TA, Donaldson AN, Yemoto CE, McNeal JE, Sözen S et al. Histological and clinical findings in 896 consecutive prostates treated only with radical retropubic prostatectomy: epidemiologic significance of annual changes. J Urol 1998; 160: 2412-7.

22 Ryan CJ, Elkin EP, Cowan J, Carroll PR. Initial treatment patterns and outcome of contemporary prostate cancer patients with bone metastases at initial presentation: data from CaPSURE. Cancer 2007; 110: 81-6.

23 Kupelian PA, Reddy CA, Reuther AM, Mahadevan A, Ciezki JP et al. Aggressiveness of familial prostate cancer. J Clin Oncol 2006; 24: 3445-50.

24 Roupret M, Fromont G, Bitker MO, Gattegno B, Vallancien G et al. Outcome after radical prostatectomy in young men with or without a family history of prostate cancer. Urology 2006; 67: 1028-32.

25 Rossi CJ Jr, Slater JD, Yonemoto LT, Jabola BR, Bush DA et al. Influence of patient age on biochemical freedom from disease in patients undergoing conformal proton radiotherapy of organ-confined prostate cancer. Urology 2004; 64: 729-32.

26 Nguyen TD, Poortmans PM, van der Hulst M, Studer G, Pigois E et al. The curative role of radiotherapy in adenocarcinoma of the prostate in patients under 55 years of age: a Rare Cancer Network retrospective study. Radiother Oncol 2005; 77: 286-9.

27 Shapiro EY, Rais-Bahrami S, Morgenstern C, Napolitano B, Richstone L et al. Long term outcomes in younger men following permanent prostate brachytherapy. J Urol 2009; 181: 1665-71. 